\title{
First report of Cytauxzoon sp. infection in Germany: organism description and molecular confirmation in a domestic cat
}

\author{
Luciana Cătălina Panait ${ }^{1}$ (D) - Graham Stock ${ }^{2} \cdot$ Majda Globokar $^{2}$ (D) - Jörg Balzer ${ }^{2} \cdot$ Bernhard Groth $^{3}$. \\ Andrei Daniel Mihalca ${ }^{1}$ (D) $\cdot$ Nikola Pantchev $^{2}$
}

Received: 1 April 2020 / Accepted: 9 July 2020 / Published online: 17 July 2020

(C) Springer-Verlag GmbH Germany, part of Springer Nature 2020

\begin{abstract}
Cytauxzoonosis is described as an emerging tick-borne disease of domestic and wild felids caused by protozoans of the genus Cytauxzoon. While in the Americas the condition is described as a fatal disease, in Europe, reports on the clinical expression of the infection are scarce. This study describes the first case of Cytauxzoon sp. infection in Germany, in a domestic cat. A 6-yearold male domestic cat living in Saarlouis (Saarland) was presented with anorexia, lethargy and weight loss. The cat had an outdoor lifestyle and had not travelled abroad. Serum clinical chemistry analysis revealed azotaemia with markedly increased symmetric dimethylarginine, hypercreatinemia, hyperphosphatemia and hypoalbuminemia. Moreover, a mild non-regenerative anaemia was present. Approximately 1 year prior to these findings, the domestic cat was diagnosed with a feline immunodeficiency virus (FIV) infection. These results pointed toward a decreased glomerular filtration rate, presumably as a result of kidney dysfunction. Round to oval signet ring-shaped intraerythrocytic organisms, morphologically suggestive for a piroplasm, were revealed during blood smear evaluation with a degree of parasitaemia of $33.0 \%$. PCR analyses and sequencing of a region of the 18S rRNA gene confirmed the presence of a Cytauxzoon sp. infection, with 99-100\% nucleotide sequence identity with previously published Cytauxzoon sp. isolates. As this is the first molecularly confirmed Cytauxzoon sp. infection in a domestic cat in Germany, these findings suggest that cytauxzoonosis should be considered as a differential diagnosis in cases of anaemia in outdoor domestic cats, particularly in areas where wild felid populations are present.
\end{abstract}

Keywords Cytauxzoon sp. · Domestic cat · FIV · Germany · PCR · Vector-borne disease

\section{Introduction}

In recent years, Cytauxzoon felis, a tick-borne pathogen of felids endemic in North America, is gaining clinical importance. Domestic cats infected with C. felis generally develop a peracute and highly fatal disease (Cohn and Birkenheuer 2012).

Furthermore, other closely related piroplasms infecting domestic and wild felids have been reported. Cytauxzoon manul was described in naturally infected Pallas's cats (Otocolobus
Section Editor: Leonhard Schnittger

Luciana Cătălina Panait

luciana.rus@usamvcluj.ro

Graham Stock

Graham-Stock@idexx.com

Majda Globokar

Majda-GlobokarVrhovec@idexx.com

Jörg Balzer

Joerg-Balzer@idexx.com

Bernhard Groth

tierarztpraxisdrgroth@gmail.com
Andrei Daniel Mihalca

amihalca@usamvcluj.ro

Nikola Pantchev

Nikola-Pantchev@idexx.com

1 Department of Parasitology and Parasitic Diseases, Faculty of Veterinary Medicine, University of Agricultural Sciences and Veterinary Medicine of Cluj-Napoca, 400372 Cluj-Napoca, Romania

IDEXX Laboratories, 70806 Kornwestheim, Germany

3 Vet Practice, 66740, Saarlouis, Germany 
manul) from Mongolia (Ketz-Riley et al. 2003; Reichard et al. 2005). In Europe, an unnamed species of Cytauxzoon was reported not only in domestic cats from Spain (CriadoFornelio et al. 2004; Díaz-Regañón et al. 2017), France (Criado-Fornelio et al. 2009; Legroux et al. 2017), Italy (Carli et al. 2012, 2014), Portugal (Alho et al. 2016) and Switzerland (Nentwig et al. 2018) but also in wild cats (Felis silvestris) in Spain (Barandika et al. 2016; León et al. 2017), Romania (Gallusová et al. 2016), Italy (Veronesi et al. 2016) and Bosnia and Herzegovina (Hodžić et al. 2018), Iberian lynx (Lynx pardinus) in Spain (Luaces et al. 2005; Millán et al. 2007, 2009; Meli et al. 2009; García-Bocanegra et al. 2010) and Eurasian lynx (Lynx lynx) in Romania (Gallusová et al. 2016). Studies on Cytauxzoon sp. in Europe show different infection rates depending on countries and host species involved. While the infection rate in domestic cats is ranging from $0.8 \%$ in France (Criado-Fornelio et al. 2009) to $23 \%$ in Italy (Carli et al. 2012), in wild felids, the assessed prevalence is generally higher than 50\% in Romania (Gallusová et al. 2016), Bosnia and Herzegovina (Hodžić et al. 2018) and Spain (Barandika et al. 2016; León et al. 2017).

The European isolates of Cytauxzoon seem to be less virulent than C. felis, and the clinical manifestations appear to be associated with immune-mediated diseases or secondary infections (Díaz-Regañón et al. 2017; Nentwig et al. 2018). However, reports of Cytauxzoon sp. infections in Europe are scarce and most of them refer to subclinical cases. Nonspecific clinical signs such as lethargy, anorexia, anaemia, fever, weight loss, tachycardia, tachypnoea, diarrhoea and vomiting have also been described (Carli et al. 2012, 2014; Alho et al. 2016; Legroux et al. 2017).

The present paper reports the first molecular confirmation of Cytauxzoon sp. infection in Germany and provides a detailed clinical picture of the disease in association with feline immunodeficiency virus (FIV) infection.

\section{Methods}

\section{Case report}

In March 2017, a 6-year-old male domestic cat was referred to a veterinary facility in Saarlouis $\left(49.31^{\circ} \mathrm{N}, 6.75^{\circ} \mathrm{E}\right)$, a small city located in Saarland (south-western Germany), with anorexia and lethargy. The cat had an outdoor lifestyle and had never travelled abroad. According to the owner, the patient had refused to eat in the last 3 days and lost approximately $1.5 \mathrm{~kg}$ in the previous few weeks. Episodes of vomiting could not be excluded due to the outdoor lifestyle of the cat. The patient received supportive therapy for 5 days with maropitant citrate (Cerenia $\left.{ }^{\circledR}, 1 \mathrm{mg} / \mathrm{kg}, \mathrm{SC}\right)$, metamizole (Novalgin ${ }^{\circledR}$; $35 \mathrm{mg} / \mathrm{kg}, \mathrm{IM}$ ), amoxicillin (Betamox ${ }^{\circledR}$ long acting $150 \mathrm{mg} / \mathrm{ml}, 15 \mathrm{mg} / \mathrm{kg}, \mathrm{SC}$ ) and fluids (Lactated Ringer's solution, $15 \mathrm{ml} / \mathrm{kg}, \mathrm{SC}$ ). Despite the therapy, the cat was euthanized on the 5th day, due to the worsening of the clinical state, being presented in a lateral decubitus with severe lethargy and ataxia. Nevertheless, the owner elected against necropsy. No information regarding the history of tick infestation or previous antiparasitic treatments was available.

\section{Clinical blood analyses}

In March 2017, a complete blood count and serum clinical biochemical analysis (including the assessment of liver, kidney and pancreatic parameters) were performed at IDEXX reference laboratory in Ludwigsburg, Germany (Table 1). Symmetric dimethylarginine (SDMA) was measured using a commercially available high-throughput immunoassay (IDEXX SDMA Test, IDEXX Laboratories Inc.; Ernst et al. 2018). No urine examination was performed.

Approximately 1 year prior to these investigations (January 2016), a blood sample from the same patient was sent to IDEXX laboratories for similar haematologic and clinical biochemical analysis (Table 1). At that time, the blood sample was also tested for feline leukaemia virus (FeLV) antigen (p27; PetChek FeLV, IDEXX Laboratories Inc.), as well as for antibodies against FIV (p24/gp40; PetChek Plus Anti-FIV, IDEXX Laboratories Inc.) and feline coronavirus (FCoV) (FCoV ELISA cat, Afosa, Germany).

\section{Microscopic examination of blood smears}

In March 2017, May-Grünwald-Giemsa-stained blood smears were prepared from peripheral blood and were evaluated for the presence of blood pathogens. The degree of parasitaemia was estimated by counting the number of infected erythrocytes per 2000 erythrocytes with an Olympus BX61 microscope at $\times 1000$ magnification. The measurement of the well-defined organisms (with a characteristic shape, $n=100$ ) was assessed with a DP72 camera and Cell ${ }^{\wedge}$ s software (Olympus Corporation, Japan).

\section{Molecular analyses and DNA sequencing}

Total nucleic acids were extracted using the QIAamp DNA Blood BioRobot MDx kit (Qiagen, Hilden, Germany) following the manufacturer's instructions. A polymerase chain reaction (PCR) assay for Piroplasmida targeting the 18S rRNA gene was performed according to Carret et al. (1999) and Katargina et al. (2011). Furthermore, a nested and a conventional PCR protocol were used for the amplification of a part of the 18S rRNA gene of the phylum Apicomplexa using primer pairs BTH-1F/BTH-1R, GF2/GR2 and 7549/7548, respectively, following previously published reaction procedures and protocols (Reichard et al. 2005; Hrazdilová et al. 2019). PCR products were visualized by electrophoresis in a $2 \%$ agarose gel. After purification, the amplicons were 
Table 1 Clinico-pathological values at March 2017 and January 2016, compared with reference values; for clinical chemistry, only abnormal values were included

\begin{tabular}{|c|c|c|c|}
\hline Parameter & Measured value (unit) in 2016 & Measured value (unit) in 2017 & Reference interval (unit) \\
\hline Urea nitrogen & $26 \mathrm{mg} / \mathrm{dl}$ & $69 \mathrm{mg} / \mathrm{dl}$ & $16-38(\mathrm{mg} / \mathrm{dl})$ \\
\hline Creatinine & $0.9 \mathrm{mg} / \mathrm{dl}$ & $2.8 \mathrm{mg} / \mathrm{dl}$ & $<1.9(\mathrm{mg} / \mathrm{dl})$ \\
\hline Phosphate & $1.5 \mathrm{mmol} / 1$ & $2.4 \mathrm{mmol} / \mathrm{l}$ & $0.8-2.2(\mathrm{mmol} / \mathrm{l})$ \\
\hline SDMA & $4 \mu \mathrm{g} / \mathrm{dl}$ & $45 \mu \mathrm{g} / \mathrm{dl}$ & $\leq 14(\mu \mathrm{g} / \mathrm{dl})$ \\
\hline Albumin & $4.4 \mathrm{~g} / \mathrm{dl}$ & $1.8 \mathrm{~g} / \mathrm{dl}$ & $2.7-4.4(\mathrm{~g} / \mathrm{dl})$ \\
\hline Albumin-globulin ratio & 1.52 & 0.35 & $>0.57$ \\
\hline Alkaline phosphatase & $77 \mathrm{U} / 1$ & $162 \mathrm{U} / \mathrm{l}$ & $<73(\mathrm{U} / \mathrm{I})$ \\
\hline Erythrocytes & $10.1 \mathrm{~T} / 1$ & $6.5 \mathrm{~T} / \mathrm{l}$ & $7.1-11.5(\mathrm{~T} / \mathrm{I})$ \\
\hline Haemoglobin & $13.4 \mathrm{~g} / \mathrm{dl}$ & $8.9 \mathrm{~g} / \mathrm{dl}$ & $10.3-16.2(\mathrm{~g} / \mathrm{dl})$ \\
\hline Haematocrit & 43 & 29.2 & $28.2-52.7 \%$ \\
\hline $\mathrm{MCV}$ & 43 & 44.9 & $39-56$ (fl) \\
\hline $\mathrm{MCH}$ & 13 & 13.7 & $12.6-16.5(\mathrm{pg} /$ cell $)$ \\
\hline $\mathrm{MCHC}$ & 31 & 30.6 & $28.5-37.8(\mathrm{~g} / \mathrm{dl})$ \\
\hline Thrombocytes & 275 & 186 & $155-641(\mathrm{G} / \mathrm{l})$ \\
\hline Reticulocytes & $37,000 / \mu \mathrm{l}$ & $15,000 / \mu \mathrm{l}$ & $\geq 50,000 / \mu l$ (when anaemic) \\
\hline Leukocytes & 8.2 & 18.2 & $3.9-19(\mathrm{G} / 1)$ \\
\hline Neutrophils & $6231 / \mu 1$ & $16,781 / \mu \mathrm{l}$ & $2620-15,170 / \mu 1$ \\
\hline Lymphocytes & 1575 & 912 & $850-5850 / \mu \mathrm{l}$ \\
\hline Monocytes & $320 / \mu \mathrm{l}$ & $547 / \mu \mathrm{l}$ & $40-530 / \mu \mathrm{l}$ \\
\hline
\end{tabular}

Abnormal results are set in bold

submitted for sequencing on both strands (Macrogen, the Netherlands). Consensus sequences were compared with sequences available in GenBank ${ }^{\mathrm{TM}}$ dataset by Basic Local Alignment Search Tool (BLAST) analysis.

\section{Results}

\section{Haematology and blood biochemistry}

In March 2017, the haematological analyses revealed azotaemia with markedly increased SDMA, hypercreatinemia, as well as hyperphosphatemia and hypoalbuminemia. Furthermore, a mild non-regenerative anaemia was present. Abnormal laboratory findings are shown in Table 1. The results indicated decreased glomerular filtration rate that suggested the presence of kidney disease. Urinalysis was not performed to assess specific gravity, protein concentration or sediment.

In January 2016, the haematological and clinical chemistry variables had been within normal limits. FeLV and FCoV tests were negative, but a positive FIV antibody test was obtained.

\section{Blood smear microscopy}

Blood smear examination in March 2017 revealed morphologically inconspicuous leukocytes, and erythrocytes displayed no significant anisocytosis or polychromasia. Blood smear evaluation revealed round to oval signet ringshaped organisms inside the erythrocytes, with a light blue cytoplasm and a blue nucleus usually located in an eccentric position (Fig. 1).

One to four merozoites were observed within individual red blood cells. The mean length of the well-defined forms was $1.2 \pm 0.2 \mu \mathrm{m}$, and the measured width was $1.0 \pm 0.2 \mu \mathrm{m}$. The intensity of parasitaemia was estimated at $33.0 \%$. The intracellular parasites were morphologically suggestive for a piroplasm. Moreover, the typical signet ring-shaped organisms could be clearly differentiated from feline haemotropic mycoplasma due to their evident large nuclear area (Cohn and Birkenheuer 2012).

Microscopic examination of a blood smear in January 2016 had revealed no blood cell morphologic abnormalities and no microorganisms.

\section{Molecular detection and characterization}

The presence of Cytauxzoon sp. DNA was confirmed by positive PCR results in all three protocols and subsequent sequencing. The longest consensus sequence available (1010 bp) was submitted to GenBank ${ }^{\mathrm{TM}}$ under the accession number MN629916. BLAST analysis of the sequenced 18S rRNA gene region revealed $99.9 \%$ nucleotide sequence identity with a GenBank ${ }^{\mathrm{TM}}$ sequence of Cytauxzoon sp. 


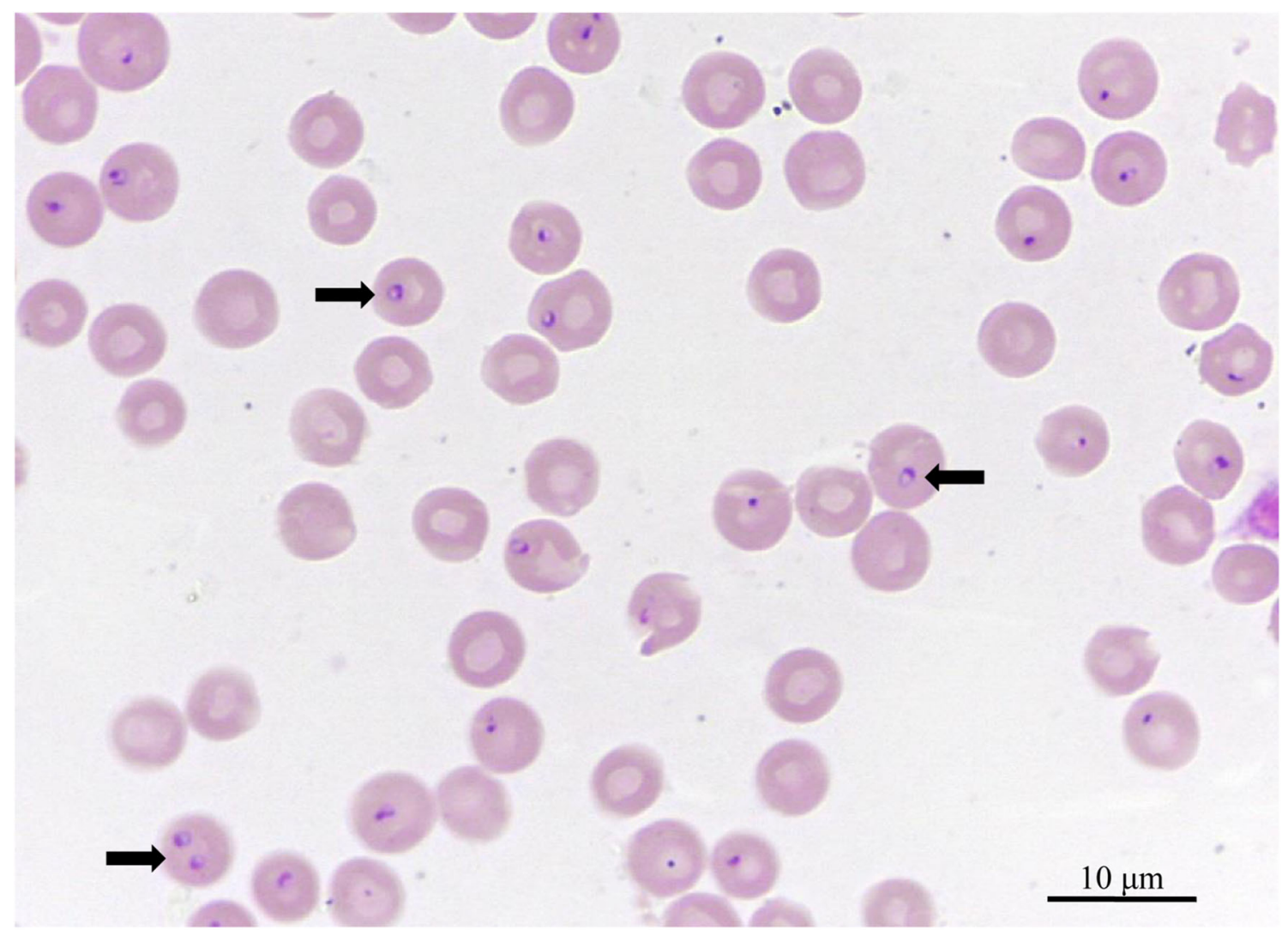

Fig. 1 May-Grünwald-Giemsa stained peripheral blood smear $(\times 1000)$. Cytauxzoon sp. appears as single or paired signet ring-shaped organisms (arrows) within erythrocytes. A high parasitaemia can be observed

originating from a domestic cat from France (accession number EU622908). Moreover, similarities of $100 \%$ were observed with sequences of Cytauxzoon sp. (MF503141, MF503143-6, KU306941-3, KU306945-8; KX881967) obtained from pet cats from Switzerland and France with clinical cytauxzoonosis (Legroux et al. 2017; Nentwig et al. 2018).

\section{Discussion}

The study reported herein describes the clinical picture, laboratory findings and diagnostic procedures of a Cytauxzoon sp. clinical infection in a domestic cat from Germany. A previous piroplasmid fatal infection was described in a captive Bengal tiger from a zoo in Germany, when parasitic inclusions resembling Cytauxzoon spp. were visualized in histological sections of various tissues, the largest number being found in blood vessels of lymph nodes and spleen. Even though there was no evidence of tick infestation of the tiger, three bobcats (Lynx rufus) originating from an American zoo were incriminated as a possible source of the infection (Jakob and Wesemeier 1996).

The cat patient in the current report was also diagnosed with a FIV infection, being presented in a critical condition a few days following clinical examination due to suspected kidney disease. Since clinical cases of canine babesiosis and theilerioses are associated with acute or chronic nephropathy or glomerulonephritis (Camacho-García 2006; SolanoGallego et al. 2016), the renal disturbances observed in this patient could have been attributed to the piroplasmid infection to FIV or both. Moreover, in C. felis infection, several cases of concomitant kidney disorders have been described in domestic and wild felids (Meier and Moore 2000; Peixoto et al. 2007; Lewis et al. 2012). Previous studies have also confirmed that FIV infection can induce the accumulation of immune complexes in renal tissue; therefore, a causative relationship between FIV infection and glomerulonephritis has been posited (Reinacher and Frese 1991; Poli et al. 1995; Harley and Langston 2012; Hosie et al. 2009). In the light of this information and the laboratory results (hypoalbuminemia pointing toward a renal loss of protein, increased creatinine and phosphate values as well as a very high SDMA value), one could postulate that the patient had glomerular disease due to immune-complex deposition in terms of a membranoproliferative glomerulonephritis. Other potential causes of hypalbuminaemia in this patient would include decreased production, other causes of loss (i.e. blood loss and protein-losing enteropathy) or haemodilution. In cases of renal injury, SDMA serum concentration increases earlier than creatinine, remaining elevated also in cases of chronic kidney 
disease (on average with $40 \%$ reduction of glomerular filtration rate, compared with up to $75 \%$ reduction needed to increase the creatinine value) (Relford et al. 2016).

Regarding the pathogenesis of FIV infection, cats remain subclinically infected for several years until functional immunodeficiency (by increasing the susceptibility to secondary infections and neoplasia) and/or immune-mediated diseases will eventually translate into clinical manifestation around 4 to 6 years of age or older (Hosie et al. 2009). In the present case, the cat did not display any noticeable clinical signs at 5 years of age, approximately 1 year before merozoites resembling Cytauxzoon sp. were detected in high numbers in the blood smear. Therefore, it can be presumed that, as a result of immunosuppression caused by FIV, the piroplasm contributed as an opportunistic factor triggering the clinical picture. Furthermore, an increased pathogenicity in association with immunosuppression induced by concurrent diseases has been previously suggested in Cytauxzoon sp. infection (Carli et al. 2012; Díaz-Regañón et al. 2017). However, the clinical role of Cytauxzoon sp. in domestic cats without immunosuppression and coinfections remains debatable, as the information about pathogenesis and clinical involvement is limited. Although some cases of clinical illness and fatal outcome have been described (Alho et al. 2016; Legroux et al. 2017; Nentwig et al. 2018), the majority of Cytauxzoon sp. infected cats were apparently healthy, with only few animals showing mild anaemia (Carli et al. 2012, 2014; Díaz-Regañón et al. 2017; Nentwig et al. 2018).

Microscopic examination of the blood smear revealed a degree of parasitaemia of $33 \%$. Other clinical studies showed lower levels of parasitaemia (Luaces et al. 2005; Carli et al. 2012, 2014; Legroux et al. 2017), while similar percentages of piroplasminfected erythrocytes were observed in the blood smear of three cats with cytauxzoonosis from Switzerland (Nentwig et al. 2018).

As the molecular confirmation of Cytauxzoon sp. infection was established post-mortem, no specific anti-piroplasm treatment was applied. Although, in C. felis infection, the recommended therapeutic protocol consists of atovaquone and azithromycin (Cohn et al. 2011), the optimal therapy for Cytauxzoon sp. infection remains unknown due to the lack of controlled clinical studies. In a recently published case report, three 2-month-old kittens infected with Cytauxzoon sp. were treated with a combination of atovaquone and azithromycin, with a putative success (Nentwig et al. 2018). Also, previously published Cytauxzoon sp. infections in domestic cats have been medicated with various antiprotozoal drugs, including imidocarb dipropionate and doxycycline (Carli et al. 2012, 2014; Alho et al. 2016; Legroux et al. 2017). Clinical studies in Europe reported that a single imidocarb dipropionate administration was not successful in treating cytauxzoonosis, although the addition of doxycycline cleared parasitaemia in another patient (Carli et al. 2014; Legroux et al. 2017).
Based on the sequencing results performed on the $18 \mathrm{~S}$ rRNA gene amplification product, Cytauxzoon $\mathrm{sp}$. detected in the present case revealed a high homology (99-100\%) with Cytauxzoon sp. reported in European domestic felids (Legroux et al. 2017; Nentwig et al. 2018) and with Cytauxzoon manul (99.8\%) described from Pallas's cats from Mongolia (Reichard et al. 2005). In contrast, the sequence displayed a more distant identity of $95 \%$ to C. felis $18 \mathrm{~S}$ rRNA partial sequences deposited in GenBank ${ }^{\circledR}$.

A significant association between the detection of Cytauxzoon sp. DNA in European domestic cats and outdoor lifestyle has been reported, particularly in rural areas (Carli et al. 2012; Díaz-Regañón et al. 2017). In agreement with these reports, the cat from the present study showed an outdoor lifestyle, which entails a higher risk of infection due to exposure to tick vectors and wildlife reservoirs. For $C$. felis infections of domestic cats, the American bobcat (L. rufus) is assumed to act as the main reservoir (Kier et al. 1982) and Amblyomma americanum and Dermacentor variabilis are the confirmed tick vectors (Blouin et al. 1984; Reichard et al. 1991). However, for the European isolates of Cytauxzoon sp., little is known about vectors and routes of transmission. In Europe, high prevalences of Cytauxzoon sp. infection were found in Felis silvestris in Romania (Gallusová et al. 2016), Italy (Veronesi et al. 2016), Bosnia and Herzegovina (Hodžić et al. 2018) and Spain (Barandika et al. 2016; León et al. 2017). Moreover, Germany has one of the biggest European populations of $F$. silvestris, which is concentrated in the low altitude mountain areas (Balzer et al. 2018). Studies on wild animal distribution suggest that Saarlouis city is surrounded by an abundant wild cat population (Steyer et al. 2016). Consequently, considering that they might live in close proximity to urban and rural areas and crossbreed with domestic cats, it is possible that wild cats play a central role in the transmission of Cytauxzoon sp. in West Germany as well as in other European countries. Ixodes ricinus is the most commonly found tick in Germany (Petney et al. 2012), and it has been hypothesised to be a possible vector for Cytauxzoon sp. (Gallusová et al. 2016).

This study describes, to the best of our knowledge, the first case of molecularly confirmed Cytauxzoon sp. infection in Germany.

\section{Conclusions}

This case provides a new geographical record of Cytauxzoon sp. infection in domestic cats in Central Europe and describes the clinical and laboratory findings in association with FIV infection. Results advocate that cytauxzoonosis should be considered as a differential diagnosis in cases of anaemia in domestic cats with an outdoor lifestyle, particularly in areas where populations of wild felids are present. Additional 
studies are required to identify the possible arthropod vectors which may be involved in the transmission and to clarify the relationship between Cytauxzoon sp. infection in cats and the presented clinical signs.

Code availability Not applicable.

Author contributions Conceptualization: Luciana Cătălina Panait, Andrei Daniel Mihalca, Nikola Pantchev; methodology: Luciana Cătălina Panait, Andrei Daniel Mihalca, Nikola Pantchev; formal analysis and investigation: Luciana Cătălina Panait, Graham Stock, Majda Globokar, Jörg Balzer, Bernhard Groth, Nikola Pantchev; writingoriginal draft preparation: Luciana Cătălina Panait, Nikola Pantchev; writing - review and editing: Luciana Cătălina Panait, Graham Stock, Majda Globokar, Jörg Balzer, Bernhard Groth, Andrei Daniel Mihalca, Nikola Pantchev; funding acquisition: Andrei Daniel Mihalca; resources: Andrei Daniel Mihalca, Nikola Pantchev; supervision: Andrei Daniel Mihalca, Nikola Pantchev.

Funding information Part of the work was supported by the Executive Agency for Higher Education, Research, Development and Innovation Funding (UEFISCDI) Grant Agency Romania, grant number PCCDI 57/ 2018 .

Data availability All data generated or analysed during this study are included in this published article.

\section{Compliance with ethical standards}

Conflict of interest The authors declare that they have no conflict of interest.

Ethics approval All clinical procedures were done as part of the diagnostic workup and treatment of the cat.

Consent to participate Not applicable.

Consent to publish Not applicable.

\section{References}

Alho AM, Silva J, Fonseca MJ, Santos F, Nunes C, de Carvalho LM, Rodrigues M, Cardoso L (2016) First report of Cytauxzoon sp. infection in a domestic cat from Portugal. Parasit Vectors 9:220. https://doi.org/10.1186/s13071-016-1506-5

Balzer S, Mölich T, Streif S, Tiesmeyer A, Thein J, Nowak C (2018) Status der Wildkatze in Deutschland. Nat Landsch 93:146-152. https://doi.org/10.17433/4.2018.50153561.146-152 (In German)

Barandika JF, Espí A, Oporto B, Del Cerro A, Barral M, Povedano I, García-Pérez AL, Hurtado A (2016) Occurrence and genetic diversity of piroplasms and other apicomplexa in wild carnivores. Parasitol Open 2. https://doi.org/10.1017/pao.2016.4

Blouin EF, Kocan AA, Glenn BL, Kocan KM, Hair JA (1984) Transmission of Cytauxzoon felis Kier, 1979 from bobcats, Felis rufus (Schreber), to domestic cats by Dermacentor variabilis (Say). J Wildl Dis 20:241-242. https://doi.org/10.7589/0090-355820.3.241

Camacho-García AT (2006) Piroplasma infection in dogs in northern Spain. Vet Parasitol 138:97-102. https://doi.org/10.1016/j.vetpar. 2006.01.043
Carli E, Trotta M, Chinelli R, Drigo M, Sinigoi L, Tosolini P, Furlanello T, Millotti A, Caldin M, Solano-Gallego L (2012) Cytauxzoon sp. infection in the first endemic focus described in domestic cats in Europe. Vet Parasitol 183:343-352. https://doi.org/10.1016/j. vetpar.2011.07.025

Carli E, Trotta M, Bianchi E, Furlanello T, Caldin M, Pietrobelli M, Solano-Gallego L (2014) Cytauxzoon sp. infection in two free ranging young cats: clinicopathological findings, therapy and follow up. Turkiye Parazitol Derg 38:185-189. https://doi.org/10.5152/tpd. 2014.3540

Carret C, Walas F, Carcy B, Grande N, Précigout É, Moubri K, Schetters TP, Gorenflot A (1999) Babesia canis canis, Babesia canis vogeli, Babesia canis rossi: differentiation of the three subspecies by a restriction fragment length polymorphism analysis on amplified small subunit ribosomal RNA genes. J Eukaryot Microbiol 46:298-301. https://doi.org/10.1111/j.1550-7408.1999.tb05128.x

Cohn LA, Birkenheuer AJ (2012) Cytauxzoonosis. In: Sykes L, Greene C (eds) Infectious diseases of the dog and cat, 4th edn. Elsevier Saunders, St Louis, pp 764-771

Cohn LA, Birkenheuer AJ, Brunker JD, Ratcliff ER, Craig AW (2011) Efficacy of atovaquone and azithromycin or imidocarb dipropionate in cats with acute cytauxzoonosis. J Vet Intern Med 25:55-60. https://doi.org/10.1111/j.1939-1676.2010.0646.x

Criado-Fornelio A, Gónzalez-del-Rıo MA, Buling-Saraña A, BarbaCarretero JC (2004) The "expanding universe" of piroplasms. Vet Parasitol 119:337-345. https://doi.org/10.1016/j.vetpar.2003.11. 015

Criado-Fornelio A, Buling A, Pingret JL, Etievant M, Boucraut-Baralon C, Alongi A, Agnone A, Torina A (2009) Hemoprotozoa of domestic animals in France: prevalence and molecular characterization. Vet Parasitol 159:73-76. https://doi.org/10.1016/j.vetpar.2008.10. 012

Díaz-Regañón D, Villaescusa A, Ayllón T, Rodríguez-Franco F, Baneth G, Calleja-Bueno L, García-Sancho M, Agulla B, Sainz Á (2017) Molecular detection of Hepatozoon spp. and Cytauxzoon sp. in domestic and stray cats from Madrid, Spain. Parasit Vectors 10:112. https://doi.org/10.1186/s13071-017-2056-1

Ernst R, Ogeer J, McCrann D, Cross J, Strong-Townsend M, Friis H, Coyne M, Clements C, Drake C, Murphy R (2018) Comparative performance of IDEXX SDMA test and the DLD SDMA ELISA for the measurement of SDMA in canine and feline serum. PLoS One 13:e0205030. https://doi.org/10.1371/journal.pone.0205030

Gallusová M, Jirsová D, Mihalca AD, Gherman CM, D’Amico G, Qablan MA, Modrý D (2016) Cytauxzoon infections in wild felids from Carpathian-Danubian-Pontic space: further evidence for a different Cytauxzoon species in European felids. J Parasitol 102:377380. https://doi.org/10.1645/15-881

García-Bocanegra I, Dubey JP, Martínez F, Vargas A, Cabezón O, Zorrilla I, Arenas A, Almería S (2010) Factors affecting seroprevalence of Toxoplasma gondii in the endangered Iberian lynx ( Lynx pardinus). Vet Parasitol 167:36-42. https://doi.org/10.1016/j. vetpar.2009.09.044

Harley L, Langston C (2012) Proteinuria in dogs and cats. Can Vet J 53: 631-638

Hodžić A, Alić A, Duscher GG (2018) High diversity of blood-associated parasites and bacteria in European wild cats in Bosnia and Herzegovina: a molecular study. Ticks Tick Borne Dis 9:589-593. https://doi.org/10.1016/j.ttbdis.2018.01.017

Hosie MJ, Addie D, Belák S, Boucraut-Baralon C, Egberink H, Frymus T, Gruffydd-Jones T, Hartmann K, Lloret A, Lutz H, Marsilio F (2009) Feline immunodeficiency. ABCD guidelines on prevention and management. J Feline Med Surg 11:775-784. https://doi.org/10. 1016/j.jfms.2009.05.006

Hrazdilová K, Myśliwy I, Hildebrand J, Buńkowska-Gawlik K, Janaczyk B, Perec-Matysiak A, Modrý D (2019) Paralogs vs. genotypes? Variability of Babesia canis assessed by $18 \mathrm{~S}$ rDNA and two 
mitochondrial markers. Vet Parasitol 266:103-110. https://doi.org/ 10.1016/j.vetpar.2018.12.017

Jakob W, Wesemeier HH (1996) A fatal infection in a Bengal tiger resembling cytauxzoonosis in domestic cats. J Comp Pathol 114:439 444. https://doi.org/10.1016/S0021-9975(96)80018-1

Katargina O, Geller J, Vasilenko V, Kuznetsova T, Järvekülg L, Vene S, Lundkvist A, Golovljova I (2011) Detection and characterization of Babesia species in Ixodes ticks in Estonia. Vector Borne Zoonotic Dis 11:923-928. https://doi.org/10.1089/vbz.2010.0199

Ketz-Riley CJ, Reichard MV, Van Den Bussche RA, Hoover JP, Meinkoth J, Kocan AA (2003) An intraerythrocytic small piroplasm in wild-caught Pallas's cats (Otocolobus manul) from Mongolia. J Wildl Dis 39:424-430. https://doi.org/10.7589/0090-3558-39.2.42

Kier AB, Wagner JE, Morehouse LG (1982) Experimental transmission of Cytauxzoon felis from bobcats (Lynx rufus) to domestic cats (Felis domesticus). Am J Vet Res 43:97-101

Legroux JP, Halos L, René-Martellet M, Servonnet M, Pingret JL, Bourdoiseau G, Baneth G, Chabanne L (2017) First clinical case report of Cytauxzoon sp. infection in a domestic cat in France. BMC Vet Res 13:81. https://doi.org/10.1186/s12917-017-1009-4

León CI, García-Bocanegra I, McCain E, Rodríguez E, Zorrilla I, Gómez AM, Ruiz C, Molina I, Gómez-Guillamón F (2017) Prevalence of selected pathogens in small carnivores in reintroduction areas of the Iberian lynx (Lynx pardinus). Vet Rec 180:252-255. https://doi.org/ 10.1136/vr. 104038

Lewis KM, Cohn LA, Downey ME, Whitney MS, Birkenheuer AJ (2012) Evaluation of Cytauxzoon felis infection status in captiveborn wild felids housed in an area endemic for the pathogen. J Am Vet Med A 241:1088-1092. https://doi.org/10.2460/javma.241.8. 1088

Luaces I, Aguirre E, García-Montijano M, Velarde J, Tesouro MA, Sánchez C, Galka M, Fernández P, Sainz Á (2005) First report of an intraerythrocytic small piroplasm in wild Iberian lynx (Lynx pardinus). J Wildl Dis 41:810-815. https://doi.org/10.7589/00903558-41.4.810

Meier HT, Moore LE (2000) Feline cytauxzoonosis: a case report and literature review. J Am Anim Hosp Assoc 36:493-496. https://doi. org/10.5326/15473317-36-6-493

Meli ML, Cattori V, Martínez F, López G, Vargas A, Simón MA, Zorrilla I, Muñoz A, Palomares F, López-Bao JV, Pastor J (2009) Feline leukemia virus and other pathogens as important threats to the survival of the critically endangered Iberian lynx (Lynx pardinus). PLoS One 4:e4744. https://doi.org/10.1371/journal.pone.0004744

Millán J, Naranjo V, Rodríguez A, De La Lastra JP, Mangold AJ, De La Fuente J (2007) Prevalence of infection and 18S rRNA gene sequences of Cytauxzoon species in Iberian lynx (Lynx pardinus) in Spain. Parasitology 134:995-1001. https://doi.org/10.1017/ S003118200700248X

Millán J, Candela MG, Palomares F, Cubero MJ, Rodríguez A, Barral M, de la Fuente J, Almería S, León-Vizcaíno L (2009) Disease threats to the endangered Iberian lynx (Lynx pardinus). Vet J 182:114-124. https://doi.org/10.1016/j.tvjl.2008.04.005

Nentwig A, Meli ML, Schrack J, Reichler IM, Riond B, Gloor C, Howard J, Hofmann-Lehmann R, Willi B (2018) First report of Cytauxzoon sp. infection in domestic cats in Switzerland: natural and transfusion-transmitted infections. Parasit Vectors 11:292. https:// doi.org/10.1186/s13071-018-2728-5

Peixoto PV, Soares CO, Scofield A, Santiago CD, Franca TN, Barros SS (2007) Fatal cytauxzoonosis in captive-reared lions in Brazil. Vet Parasitol 45:383-387. https://doi.org/10.1016/j.vetpar.2006.12.023

Petney TN, Pfäffle MP, Skuballa JD (2012) An annotated checklist of the ticks (Acari: Ixodida) of Germany. Syst Appl Acarol 17:115-171. https://doi.org/10.11158/saa.17.2.2

Poli A, Falcone ML, Bigalli L, Massi C, Hofmann-Lehman R, Lombardi S, Bendinelli M, Lutz H (1995) Circulating immune complexes and analysis of renal immune deposits in feline immunodeficiency virusinfected cats. Clin Exp Immunol 101:254-258. https://doi.org/10. 1111/j.1365-2249.1995.tb08347.x

Reichard MV, Meinkoth JH, Edwards AC, Snider TA, Kocan KM, Blouin EF, Little SE (1991) Transmission of Cytauxzoon felis to a domestic cat by Amblyomma americanum. Vet Parasitol 161:110 115. https://doi.org/10.1016/j.vetpar.2008.12.016

Reichard MV, Van Den Bussche RA, Meinkoth JH, Hoover JP, Kocan AA (2005) A new species of Cytauxzoon from Pallas' cat caught in Mongolia and comments on the systematic and taxonomy of piroplasmids. J Parasitol 91:420-427. https://doi.org/10.1645/GE$384 \mathrm{R}$

Reinacher M, Frese K (1991) Untersuchungen zur Glomerulonephritis bei Hund und Katze. Tierarztl Prax 19:175-180 (In German)

Relford R, Robertson J, Clements C (2016) Symmetric dimethylarginine: improving the diagnosis and staging of chronic kidney disease in small animals. Vet Clin Small Anim 46:941-960. https://doi.org/10. 1016/j.cvsm.2016.06.010

Solano-Gallego L, Sainz Á, Roura X, Estrada-Peña A, Miró G (2016) A review of canine babesiosis: the European perspective. Parasit Vectors 9:336. https://doi.org/10.1186/s13071-016-1596-0

Steyer K, Kraus RH, Mölich T, Anders O, Cocchiararo B, Frosch C, Geib A, Götz M, Herrmann M, Hupe K, Kohnen A (2016) Large-scale genetic census of an elusive carnivore, the European wildcat (Felis $s$. silvestris). Conserv Genet 17:1183-1199. https://doi.org/10.1007/ s10592-016-0853-2

Veronesi F, Ravagnan S, Cerquetella M, Carli E, Olivieri E, Santoro A, Pesaro S, Berardi S, Rossi G, Ragni B, Beraldo P (2016) First detection of Cytauxzoon spp. infection in European wildcats (Felis silvestris silvestris) of Italy. Ticks Tick Borne Dis 7:853-858. https://doi.org/10.1016/j.ttbdis.2016.04.003

Publisher's note Springer Nature remains neutral with regard to jurisdictional claims in published maps and institutional affiliations. 